\title{
Expatriação e Estratégia Internacional: o Papel da Família como Fator de Equilíbrio na Adaptação do Expatriado
}

\author{
Neuri Amabile Frigotto Pereira \\ Ricardo Pimentel \\ Heitor Takashi Kato
}

\section{Resumo}

Este artigo procura destacar, por meio de uma revisão da literatura, a importância da internacionalização da estratégia das empresas e o papel da família do trabalhador no exterior, o expatriado, no processo de seu ajustamento ao novo ambiente. Sendo o ajustamento um fator importante para o sucesso da estratégia de internacionalização, discute-se a importância da internacionalização e da expatriação, a natureza da atividade do expatriado para as empresas, os desafios a serem enfrentados e o papel da família no processo de ajustamento. Conclui-se que a família é fundamental neste ajustamento, sendo apresentadas algumas sugestões de pesquisas a serem realizadas, bem como possíveis hipóteses a serem testadas.

Palavras-chave: estratégia de internacionalização; ajustamento intercultural; expatriados; família; corporação multinacional.

\begin{abstract}
This paper focuses on the importance of the international strategy and the role of the family in the process of the expatriates' adjustment in a foreign country. Being this adjustment one of the main factors in organizations international strategy success, it is discussed, by a review of the literature, the importance of internationalization, the nature of the activity of the expatriate, the importance of them to their employers, the obstacles they confront and the role of the family to their social adjustment. The conclusion is that the family plays a critical role in expatriates' adjustment, and suggestions of new research topics, and also some hypothesis to be studied, are presented.
\end{abstract}

Key words: internationalization strategy; intercultural adjustment; expatriates; family; multinational corporation. 


\section{INTRODUÇÃO}

O crescente movimento de globalização, fusões e aquisições, alianças estratégicas e joint ventures de empresas transnacionais e multinacionais vem ocasionando aumento no número de executivos vivendo e trabalhando em país estrangeiro, denominados expatriados (SHEPHARD, 1996). De acordo com uma pesquisa realizada em 1996, o volume de expatriados tem crescido de forma agressiva. O Brasil tem sido um dos países mais afetados por este processo, sendo, no período de 1989 a 1994, o terceiro país a receber mais expatriados (14\%), atrás apenas da China (27\% de participação) e da Índia (26\%) (WINDHAM INTERNATIONAL AND NATIONAL FOREIGN TRADE COUNCIL, 1996).

Desta forma, os estudos e pesquisas que buscam compreender o processo de internacionalização das empresas ganham cada vez mais importância, teórica e prática. Dentro deste processo está a interação das diversas culturas em contato e a adaptação cultural e social dos indivíduos que necessitam mudar de país em função dos negócios.

\section{O Impacto da Internacionalização}

O impacto da internacionalização se dá em duas dimensões. A primeira diz respeito à recepção no país de empresas estrangeiras e seus executivos e funcionários. Em função da abertura de mercado implementada na primeira metade da década de 1990 , o Brasil subiu do $12^{\circ}$ país para o $3^{\circ}$ na classificação de recebimento de expatriados (WINDHAM INTERNATIONAL AND NATIONAL FOREIGN TRADE COUNCIL, 1996). A segunda dimensão referese ao processo de internacionalização das empresas brasileiras, como estratégia de sobrevivência e de crescimento em um mercado globalizado ${ }^{(1)}$.

No ano 2000, na primeira dimensão o Brasil foi o segundo maior receptor de Investimentos Estrangeiros Diretos (IED) dentre os países em desenvolvimento. Por outro lado, na outra dimensão, considerados os IEDs realizados por empresas brasileiras no estrangeiro, o Brasil ocupa a $30^{\circ}$ colocação, atrás da Malásia, Coréia, Singapura e México(2) (WORLD COMPETITIVENESS REPORT apud FUNDAÇÃO DOM CABRAL, 2002).

Nos últimos anos, países como Argentina, Brasil, Chile, Espanha, Índia e México tiveram taxas de crescimento da economia bastante reduzidas, principalmente no período 1993 a 2002. As maiores corporações de capital aberto destes países 
cresceram, no período, em média apenas 3\% em dólar. Entretanto alguns grupos empresariais conseguiram valorização de até $60 \%$ nos seus títulos, devido à característica comum da internacionalização de suas atividades, ou seja, a expansão das operações e do faturamento para fora das fronteiras do país de origem (CAETANO, 2003).

\section{O Desafio da Internacionalização}

Esta realidade de baixa presença de empresas brasileiras no exterior tem sido modificada gradativamente, e alguns exemplos bem sucedidos apresentam a oportunidade de aprendizado para outros grupos que pretendem lançar-se nesta alternativa estratégica. Atualmente, o grupo Gerdau, que ocupa a posição de maior produtor de aço longo no continente americano, tem cerca de $30 \%$ do seu faturamento oriundos de suas filiais e subsidiárias no exterior. Outro exemplo é a construtora Odebrecht, que atua fora do Brasil desde 1978: em 2002 obteve mais de $60 \%$ da sua receita total no exterior; e outro ainda, a gaúcha Marcopolo, fabricante de ônibus, para a qual mais de $50 \%$ de seu faturamento vem de fábricas em outros países, como Colômbia, México, Argentina, África do Sul e China ${ }^{(3)}$.

Segundo pesquisa da Fundação Dom Cabral (2002), realizada junto a 109 empresas de capital nacional com faturamento variando entre R \$ 5 milhões e R \$ 9,5 bilhões, $17,4 \%$ delas pretendem instalar subsidiárias no exterior (10,7\% já as possuem). O estudo mostra que uma das três principais barreiras à internacionalização identificadas por estas empresas está ligada à problemática deste artigo: barreiras internas à organização, tais como adequação de capacidades e de recursos para atuar no exterior (FUNDAÇÃO DOM CABRAL, 2002).

O mundo das atividades profissionais e de negócios é permeado por representações e práticas peculiares a cada universo cultural. Como desafio à administração, compreender essas práticas e representações torna-se necessário para que as interações e negociações interculturais, advindas da implantação de uma estratégia de internacionalização, sejam bem sucedidas (HOFSTEDE, 1980). Assim, há concordância dos especialistas em recursos humanos internacionais, quanto à importância de as empresas multinacionais manterem programas capazes de atrair, selecionar, desenvolver e reter empregados que possam viver e trabalhar eficazmente no exterior (CALIGIURI, 2000).

Neste artigo, tem-se por objetivo discutir, com base no referencial teórico, o papel que a família do expatriado exerce no processo de seu ajustamento cultural. Para tanto, em primeiro lugar discute-se a natureza da atividade do expatriado, os principais desafios a serem alcançados por ele, e alguns estudos que mostram razões de sucesso e de fracasso das expatriações. 


\section{A Natureza do Trabalho do Expatriado e a Lógica de sua Designação}

Shephard (1996) define expatriado como um indivíduo que não é cidadão do país no qual ele ou ela está designado para trabalhar. De acordo com o English - Reader's Dictionary (HORNBY, 1979), expatriado é uma pessoa vivendo longe de seu próprio país. Certo (1997) define os expatriados como os membros da organização que vivem e trabalham em país no qual eles não têm cidadania.

As motivações estratégicas que levam os expatriados a serem enviados são definidas, em geral, em função de três objetivos complementares: (1) buscar o entendimento das necessidades do mercado local, para que possa ser criada a diferenciação nos produtos para atender às preferências dos clientes e às características do setor, bem como promover as mudanças culturais e legais no ambiente de mercado onde irão operar, denominado resposta local; (2) alavancar as oportunidades de diferentes fatores da produção nacional, buscando economias de escala, compartilhamento de custos e investimentos por meio de diferentes mercados e unidades de negócios, denominado integração global; e por fim, (3) desenvolver na organização o intercâmbio das diferentes unidades (centrais ou subsidiárias), para que aprendam entre si e troquem inovações e sistemas de gestão e processos, denominado aprendizado e inovação (BARTLETT; GHOSHAL, 1992).

As principais razões pelas quais as companhias enviam expatriados para tarefas internacionais são: (1) abrir novos mercados; (2) facilitar uma fusão ou aquisição; (3) instalar novas tecnologias e sistemas; (4) aumentar a participação de mercado (market share) ou impedir que competidores o façam; (5) desenvolver visão de longo prazo de negócios em países estrangeiros; (6) transferir conhecimento para profissionais locais; (7) aprender e gerar idéias inovadoras; e (8) desenvolver habilidades de liderança global (BLACK; GREGERSEN, 1999; HALCROW, 1999).

Os problemas enfrentados pelas empresas, quando decidem ir a mercados internacionais, são numerosos e passam pela legislação, situação política e econômica, ambiente de negócios e cultura. Além de enfrentar uma variedade de diferenças em relação à forma de conduzir os negócios, elas enfrentam o desafio de escolher pessoas confiáveis, que possuam conhecimentos cruciais sobre a empresa e possuam habilidades que permitam assumir responsabilidades pelo negócio internacional.

Estudos mostram que, apesar de as empresas entenderem a necessidade de 
uma seleção efetiva de políticas de treinamento e de programas adequados, os critérios usados para selecionar e treinar os executivos expatriados são freqüentemente simplistas e rígidos. Isso ocorre porque o critério de seleção, utilizado em larga proporção nas empresas multinacionais, é a crença de que o histórico de sucesso do executivo em gerir uma companhia em determinado país, naturalmente o habilita para desenvolver seu trabalho em qualquer outro lugar com os mesmos resultados. A ênfase recai sobre os aspectos técnicos e pouco se faz no sentido de verificar qual a capacidade de adaptação do indivíduo ao contexto cultural diferente. Menor atenção ainda é dada a outros aspectos, tais como o bem-estar dos seus familiares neste novo país e a preparação deles para o novo ambiente (ALI, 2003; MENDENHALL; ODDOU, 1985).

\section{Ajustamento Cultural do Expatriado e seus Familiares: Impactos nos Resultados para as Organizações}

As nomeações de executivos para trabalhos internacionais são importantes para o sucesso das estratégias de internacionalização das companhias, pois ajudam a construir o nível global de competência e integração (ALI, 2003).

Geralmente o ajustamento cultural pode ser definido como o grau de conforto psicológico com vários aspectos do país hospedeiro (BLACK, 1990; NICHOLSON, 1984; OBERG, 1960). Zhang e Rentz (apud ALI, 2003) definem ajustamento intercultural como a habilidade de se adaptar com o ambiente cultural novo de modo eficiente e suficiente para sentir-se confortável funcionalmente como se estivesse em sua própria cultura.

Miller (1973) aborda o mesmo processo, fazendo uma relação entre o grau de ajustamento do indivíduo e o local de trabalho. Cita como exemplo norteamericanos expatriados que, designados para trabalhos na Europa, mostraramse mais satisfeitos do que aqueles designados para a América do Sul. É geralmente esperado que, quanto maior a diferença entre a cultura do país de origem e do país do destino, mais difícil se torna o ajustamento. Esta diferença tem sido chamada de choque cultural. Stening e Hamner (1992) exploram em seus estudos a adaptação cultural ao país destino, acrescentando na análise o background cultural dos expatriados. Os estudos realizados por estes pesquisadores com executivos japoneses e americanos nos Estados Unidos, Japão e Tailândia, sugerem que o background cultural dos expatriados é mais importante do que as características culturais do país hospedeiro, no processo de adaptação entre culturas ${ }^{(4)}$. 
O ajustamento cultural pode ser caracterizado em quatro estágios (BLACK; MENDENHALL; ODDOU, 1991). São eles:

. Estágio 'Lua de Mel'. Nesta fase a esposa do expatriado e os filhos usualmente estão excitados com todas as coisas novas oferecidas no novo país; neste estágio, o sentimento é idêntico ao do turista. Este período pode variar entre duas semanas e alguns meses, quando então o segundo estágio aparece.

. Estágio do Choque Cultural. Nesta fase, também chamada de fase da desilusão, a família começa a se sentir desconfortável com a vida diária no novo país. A interação com aspectos da cultura local, com comportamentos considerados não costumeiros e imprevisíveis, disparam reações de rejeição à nova cultura. Sentimentos de solidão, desconforto e desilusão aparecem; e podem causar ansiedade, stress e retorno prematuro. Esta fase que, em geral, dura de três a nove meses, requer uma reação adequada e muitos não são capazes de prosseguir para outros estágios, sendo esta a fase apontada nos estudos como crítica em termos de repatriação. Aqueles que sobrevivem a este estágio, em geral estão aptos para progredirem para o estágio do ajustamento.

. Estágio de Ajustamento. É o período no qual os membros da família do expatriado se sentem confortáveis e, gradualmente, aceitam a nova cultura, passando a entender melhor o comportamento das pessoas. Sentem-se menos isolados, mais familiarizados com os costumes e condições, aprendem com a comunidade e progressivamente tornam-se capazes de operar a rotina diária apesar de alguns distúrbios. Este estágio ocorre, em geral, entre o sexto e o décimo segundo mês.

. Estágio do Entusiasmo. Os indivíduos passam a gostar da cultura e suas rotinas diárias tornam-se fáceis de conduzir. Os aspectos positivos da nova cultura são percebidos e nasce um sentimento de pertencer ao local. Este estágio vai ocorrer após o décimo mês(5).

No processo de ajustamento cultural, mais especificamente na fase de choque cultural, a aculturação é o fator decisivo para a adaptação do indivíduo à nova sociedade. Aculturação, segundo Ferreira (1986), é a interpretação da cultura, por meio de um conjunto de fenômenos provenientes do contato direto e contínuo de grupos de indivíduos representantes de culturas diferentes.

A aculturação pode ser entendida como o processo pelo qual o membro de um grupo de um background cultural se adapta à cultura de um grupo diferente (RIEGER; RIEGER apud TUNG, 1998). Com base nestas duas dimensões, quatro orientações básicas para as relações entre grupos culturais são mencionadas: 
. Integração. Atração pela cultura do outro grupo cultural com preservação das normas da própria cultura.

- Assimilação. Atração pela cultura do outro grupo cultural, mas não preservando as normas da própria cultura.

. Separação / segregação. Preservação das normas da própria cultura com rejeição da cultura do outro grupo.

. Marginalização. Não preservação das normas da própria cultura e rejeição da cultura do outro grupo.

Duas dimensões da aculturação podem ser identificadas: (1) a preservação cultural, definida como a extensão que cada membro de um subgrupo cultural precisa preservar de suas próprias normas culturais; e (2) a atratividade da sociedade parceira, definida como a extensão na qual os membros de um subgrupo cultural são atraídos pelas normas de uma grande sociedade onde eles operam (BERRY; KALIN, 1995).

Estudos realizados com uma população de imigrantes e expatriados mostraram que a integração é a forma ótima de interação das pessoas de duas culturas, pois permite que as pessoas que adotam esta orientação se integrem à outra cultura e, ao mesmo tempo, continuem leais à sua própria cultura. No outro extremo (e de modo mais prejudicial), está a marginalização, situação em que o indivíduo perde totalmente a identidade. Entre estes dois extremos estão a assimilação e a separação (BERRY; KALIN, 1995).

\section{O Desafio do Ajustamento do Expatriado}

De todos os gestores americanos enviados para outros países, de $10 \%$ a $20 \%$ retornaram antes do tempo previsto, devido à insatisfação com o trabalho ou dificuldades de se ajustar a um país estrangeiro. Para aqueles que completaram a missão, perto de um terço não alcançou o nível de desempenho esperado pelos seus superiores (BLACK; GREGERSEN, 1999; TUNG, 1982). Outros estudos apontam taxas de fracasso de expatriados que flutuam entre 25 e $40 \%$, com um custo bastante elevado para as companhias (MISA; FABRICATORE, 1979).

A falta de habilidade dos expatriados em se ajustarem à cultura social e ao ambiente de negócios dos países hospedeiros tem altos custos em termos de desempenho gerencial, produtividade nas operações no exterior, na relação com clientes e na eficiência operacional.

O grau de fracasso nas missões de negócios internacionais pode variar em 
termos de relevância. Um expatriado que fica na posição, mas com problemas de adaptação, pode incorrer em custos diretos e indiretos para as companhias, e para o próprio indivíduo e seus familiares. Os custos diretos anuais, decorrentes do processo de repatriação por conta de retorno prematuro de profissionais, é de aproximadamente US\$ 2 bilhões (BLACK; GREGERSEN, 1999). Os custos indiretos incluem a redução de produtividade, perda de market share e posição competitiva, destruição da equipe de trabalho da empresa, prejuízos nas relações com clientes e fornecedores, e perda de imagem e reputação da empresa no mercado (BLACK; GREGERSEN; MENDENHALL, 1992; NAUMANN, 1992). Tung (1998) acrescenta que a manutenção de um expatriado não adaptado na função pode também ter alto custo indireto para o expatriado e seus familiares, em termos de redução de auto-estima, deterioração dos relacionamentos e interrupção de carreira.

Cabe ressaltar que apenas 16\% de todos os expatriados dos E.U.A são mulheres, mesmo considerando-se que elas respondem por $46,5 \%$ de toda a força de trabalho empregada (GMAC, 2002). Os dados apresentados justificam, no presente artigo, o enfoque dado às esposas e familiares do expatriado.

A adaptação da família e da esposa são fatores importantes associados ao sucesso ou fracasso de expatriados em suas missões (DE CIERI et al., 1991; MENDENHALL et al., 1987; SCHNEIDER; ASAKAWA, 1995). Pesquisa com 72 gestores de recursos humanos de multinacionais, responsáveis pela seleção de candidatos para trabalhar como representantes em negócios internacionais, identificou uma série de fatores chave para o sucesso de expatriados. Os três principais fatores a que se atribui o grau de sucesso dos expatriados, são: (1) adaptação intercultural; (2) habilidades técnicas para a tarefa e para gestão; (3) a estabilidade e adaptabilidade da família. Estes fatores somados justificam 70\% das razões atribuídas pelos gestores (FLYNN apud ALI, 2003).

\section{A Importância da Família no Ajustamento do Expatriado}

Ao longo das últimas duas décadas, a questão do retorno prematuro de expatriados ao país de origem tem sido um problema recorrente e crescente, enfrentado pelos administradores de pessoal das multinacionais. Estudos realizados sugerem que fatores como o não ajustamento destes executivos à cultura do país do destino e ao ambiente de negócios nestes países são as principais causas (BAKER; IVANCEVICH, 1971; MISA; FABRICATORE, 1979; TUNG, 1988; ZEIRA; BANAI, 1985).

Foram identificadas sete razões para o fracasso dos expatriados: (1) inabilidade de ajustamento da esposa do expatriado ao novo ambiente físico e cultural; (2) 
inabilidade de ajustamento do expatriado ao novo ambiente físico e cultural; (3) a personalidade do expatriado ou imaturidade emocional; (4) a falta de habilidade do expatriado em conseguir responder às responsabilidades assumidas; (5) a falta ou insuficiência de competência técnica; (6) a falta ou insuficiência de motivação para trabalhar no exterior; e por fim, (7) outros problemas de ordem familiar (TUNG, 1987). Outros estudos indicam estes altos índices de fracasso como sendo causados pela inabilidade em lidar com situações de alto stress, a insuficiência ou falta de atitudes corretas, a falta de habilidade de comunicação com pessoas de culturas diferentes, além da não adaptação da família ao novo ambiente (BLACK; GREGERSEN; MENDENHALL, 1992; MENDENHALL; DUNBAR; ODDOU, 1987).

Os desafios críticos para as empresas ao recrutar expatriados, apontados em pesquisas realizadas por organismos de comércio internacional, são o ajustamento da família (65\%), e a resistência das esposas à nova situação (53\%) (WINDHAM INTERNATIONAL AND NATIONAL FOREIGN TRADE COUNCIL, 1996). Esta pesquisa junta-se a outra realizada com gestores americanos expatriados, cujo resultado mostra que a falta de habilidade das esposas em se adaptar à cultura do país hospedeiro aparece como o fator mais importante para justificar o fracasso dos executivos (TUNG, 1987).

Por que as empresas, então, não utilizam a expatriação sem os familiares e reduzem assim o risco de insucesso? Parte da resposta está no fato de o contato que se espera que o expatriado faça com a nova cultura não é apenas na condição de observador ou estudioso, mas fundamentalmente de agente ativo, cujos recursos de atuação são oriundos da sua cultura de origem. Essa ação se dá pelo contato com os diversos elementos do ambiente no qual o expatriado irá atuar: clientes, fornecedores, órgãos de governo, formadores de opinião, entre outros. Para tanto, há a necessidade de se construir um espaço de convivência desse indivíduo com a nova cultura, que possa ser fortalecido pela presença constante e marcante dos elementos culturais de origem. Uma fonte fundamental dessa força é sem dúvida a família.

As evidências existentes nas empresas que têm expatriados reforçam esse argumento e demonstram que: a) a aceitação de tarefas em outras localidades sem a transferência dos familiares reduz substancialmente o número de candidatos disponíveis para as vagas; b) os expatriados que aceitam ir sem a família acabam sofrendo o choque cultural de forma mais significativa do que os que vão acompanhados da família; c) a adaptação cultural do expatriado, acompanhado da família, é facilitada no ambiente externo pelo apoio da família, e no trabalho é abrandada pelo conhecimento que ele tem da cultura da empresa, pela própria natureza do trabalho e pela não preocupação com outros fatores do dia-a-dia 
fora trabalho; e d) como o expatriado tem o apoio da família, a dedicação ao trabalho e às atividades designadas para seu novo posto recebe maior atenção e o grau de sucesso é maior (BLACK; STEPHENS, 1989; DE CIERI; DOWLING; TAYLOR, 1991).

Enviar a família junto com o expatriado passa a ter papel fundamental, não só na adaptação dele, mas também no sucesso na missão para a qual foi designado. De fato, é transferido para sua família o maior impacto do choque cultural a que é exposto o executivo. Embora esta transferência seja benéfica para a empresa num primeiro momento, se mal administrada poderá causar um problema para o executivo e, em decorrência, para a empresa.

Em vários sentidos o ajustamento intercultural da esposa e dos filhos é mais difícil do que o ajustamento do executivo expatriado. O expatriado, durante boa parte da semana, não entra em contato com a cultura do país em que trabalha, pois sua vida profissional encontra continuidade na empresa, onde conta com uma rede de relações que lhe dá suporte, bem como uma rede de troca de informações com o país de origem, vantagem de que a esposa e outros familiares não dispõem. Se em casa, o executivo conta com o apoio da família que, em geral, mantém a cultura do país de origem, o mesmo não pode ser dito da família. A esposa do expatriado e os filhos, por outro lado, não têm acesso à continuidade organizacional, e experimentam uma interrupção nas suas vidas pessoais, nos seus relacionamentos, na rotina diária. Além disto, encontram pouca ajuda para administrar as demandas diárias em circunstâncias fora do ambiente familiar a que estavam habituados no país de origem (DE LEON; MC PARTLIN apud ALI, 2003; HARVEY, 1985; NAUMANN, 1992).

A boa prática administrativa recomenda disponibilizar ao indivíduo que será expatriado informações sobre os aspectos relacionados à história do país do destino, sobre a religião praticada pela maioria da população, seus principais valores, as regras de convivência, interdições e tabus. Porém a realidade nem sempre corresponde àquilo que a boa prática recomenda e os quadros internacionais nem sempre têm a disponibilidade e o tempo necessários para fazer este processo de educação da pessoa designada para a tarefa internacional. Quando isso ocorre, e principalmente em situações de expatriação, as empresas que têm adotado programas de ajustamento antecipado têm como objetivo reduzir a incerteza psicológica para o indivíduo, decorrente de sair de um cenário familiar para entrar em cenário desconhecido.

Para aumentar as chances de sucesso destes programas o recomendável seria que o conteúdo abordado contivesse no mínimo as regras de decoro ou de cortesia a respeitar, mas os livros sobre cortesia, história e religião deste ou daquele país são de diferentes autores e apenas abordam as diferenças culturais em nível 
muito superficial, o que acaba por fazer com que o enviado tenha de descobrir na prática o que realmente é relevante na cultura do interlocutor estrangeiro ou do país hospedeiro. Como de modo geral isto não é observado nos programas pré-expatriação, sua validade tem sido questionada e os resultados considerados insuficientes. Os principais fatores que contribuem para isso são: (1) os programas são normalmente muito curtos, durando dois ou três dias; (2) o conteúdo fornecido é superficial; e (3) o idioma, que é fator crucial, acaba sendo relegado a segundo plano (TUNG, 1987).

Não obstante ser fácil reconhecer que as competências interculturais são importantes e facilitadoras das missões fora do país, tornando-as mais produtivas e menos dolorosas, a maioria dos gestores de recursos humanos nada fazem em termos de formação intercultural para os empregados em geral, nem mesmo para aqueles que são recrutados e selecionados para missões internacionais, causando perdas significativas para a empresa e para o próprio expatriado.

Considerando especificamente a família do expatriado, os principais fatores que contribuem para a adaptação das esposas dos expatriados são divididos em três grupos: (1) fatores individuais, tais como fluência na língua, mudanças na condição de emprego (carreira), auto-eficácia em geral, e eficácia social. Cabe ressaltar que a diferença de cultura, que começa com a língua, pode, desde logo, criar erros de compreensão dos sistemas, podendo mesmo surgir mal-entendidos logo na fase inicial de conhecimento; (2) fatores ambientais, tais como a novidade cultural (diferença entre a cultura do país de origem e o novo país), a orientação social do país hospedeiro (que inclui aspectos legais, econômicos, sociais, demográficos e políticos), os estilos cognitivos e psicossociológicos do novo país, o sistema de valores e crenças dominantes, os padrões de comunicação dominante, como língua e dialetos e a comunicação não verbal. Nesse grupo de fatores, o entendimento das diferenças culturais depende, muitas vezes, de uma abordagem multidisciplinar que inclua vertentes diferentes, como as da sociologia, economia, legislação, antropologia e psicologia social; e, por fim, (3) fatores de relacionamento interpessoal, tais como os relacionamentos familiares e as redes de relacionamentos sociais. Nesse grupo cabe ressaltar que é importante avaliar aspectos ligados ao estágio do ciclo de vida, tais como os seguintes: se o indivíduo é solteiro; casado sem filhos; casado com filhos; se está no segundo casamento etc.

Para minimizar estes impactos algumas empresas têm utilizado programas que facilitam o ajustamento do expatriado no país estrangeiro, e programas de suporte aos familiares no país hospedeiro, próprios ou terceirizados, sendo que estas companhias são as que apresentam índices de sucesso maior. O índice de sucesso para esta medição é o número de expatriados que retornam antes do final de sua missão no país estrangeiro versus o número de expatriados totais (NAUMANN, 
1992). Esses programas são organizados com dois enfoques básicos: (1) fatores relacionados ao trabalho - que são organizados de forma a incluir o expatriado no novo contexto de trabalho, ambientação com a nova função, grau de envolvimento com as pessoas, limitações técnicas e de recursos, regulamentações legais e internas entre outros; bem como definição clara do papel do expatriado na organização em relação aos objetivos , critérios de avaliação e retorno esperado; (2) fatores relacionados à cultura organizacional e fora do trabalho que visam dar suporte ao expatriado e a seus familiares - são fatores logísticos ligados às questões externas ao contexto de trabalho tais como apoio à moradia, escola, supermercados etc., instruções que visem reduzir a distância entre a cultura do país estrangeiro em relação ao país de origem (COPELAND; NORELL, 2002; SHAFFER; HARRISON, 2001).

O maior índice de sucesso é atribuído principalmente ao fato de que, havendo suporte para os primeiros meses, minimiza-se fortemente o impacto de a esposa sentir-se completamente deslocada, com uma série de decisões a serem tomadas sem qualquer parâmetro costumeiro disponível. Esse suporte pode dar-se em diversos aspectos, tais como curso de línguas, ajuda na contratação de empregados domésticos, inclusão da família em clubes e sociedades no país hospedeiro, ajuda na locação de imóvel e na escolha da escola para filhos, entre outros (ALI, 2003).

Há suficientes evidências na literatura disponível sobre a preparação prévia dos expatriados e da sua família para que isto seja considerado um fator que pode favorecer largamente a adaptação cultural a outro contexto, e assim evitar fracassos e frustrações com prejuízos profissionais e pessoais para todos os envolvidos.

Além do fator de preparação do expatriado e familiares, existe pelo menos mais uma medida preliminar, que é a seleção do executivo, como fator contributivo para a redução do risco de insucesso no processo. A grande maioria das corporações adota critérios basicamente técnicos na seleção dos expatriados, desconsiderando outros fatores, ainda que as estatísticas existentes indiquem outros caminhos a serem seguidos.

Considerando a relevância do papel da família, como um dos principais fatores no sucesso das missões atribuídas aos expatriados, as empresas poderiam adotar critérios adicionais na seleção e treinamento destes executivos, como os seguintes: a) incluir na seleção critérios de avaliação do perfil cultural da família do candidato, incluindo fatores relevantes para a adaptação no país do destino, os candidatos cuja família possua maior similaridade com a cultura do país do destino teriam preferência; b) dar preferência para expatriado ou família do expatriado que tenha tido exposição com outras culturas, ainda que não seja experiência 
profissional, como nestes exemplos: processos de intercâmbio durante a vida estudantil etc.; c) criação de programas pré-expatriação que incluam a habilidade de comunicação na língua do país hospedeiro, a disponibilização de outros elementos de contato com a nova cultura, tais como leitura de obras importantes que expressem a cultura do país hospedeiro, sejam elas de ficção, de caráter acadêmico ou mesmo jornalístico, filmes e documentários, música, bem como vivências com pessoas da nova cultura; d) continuidade do programa no país do destino, acrescido de estrutura de apoio que promova a transição do expatriado e familiares, incluindo apoio para decisão sobre escola para os filhos, cursos intensivos na língua do país do destino, cursos que demonstrem as diferenças culturais mais notáveis, como nestes exemplos: o que certas expressões significam em uma cultura e em outra; costumes considerados normais no país de origem que sejam considerados não apropriados no país do destino.

Para as empresas brasileiras, o cuidado com o apoio para os seus funcionários no exterior pode ser fundamental para uma decisão de internacionalização. Em muitos setores, o mercado brasileiro apresenta oportunidades de crescimento menores e isto pode ser uma ameaça à sobrevivência da empresa, devido à tendência de consolidação global em muitos setores. As empresas latinas enfrentam dificuldades como alta carga tributária, a escassez e elevado custo de capital na hora de concorrer com rivais internacionais (SULL; ESCOBARI, 2004). Desta forma, para empresas que optem por uma estratégia de crescimento pela expansão internacional, como a Marcopolo, Odebrecht e Gerdau, os cuidados com a adaptação dos executivos no exterior podem ser fundamentais até para a própria sobrevivência da empresa no longo prazo. "Mas, os brasileiros costumam ter mais dificuldades de se adaptar a outras culturas" (SILVEIRA, 2002). Isto se daria por nós brasileiro não termos, desde pequeno, a centelha de internacionalização correndo nas veias, ao contrário dos europeus, devido às dimensões continentais do Brasil. Neste sentido, o papel da adaptação da família neste contexto internacional pode ser ainda mais decisivo para a própria adaptação do executivo brasileiro neste contexto internacional.

\section{Conclusão e Sugestões}

Com base na revisão teórica apresentada, pode-se concluir que os aspectos culturais têm sido considerados como de grande relevância para o ajustamento da esposa, dos filhos e do próprio expatriado, e que esse ajustamento está diretamente relacionado ao dimensionamento do sucesso na jornada ao exterior, e por conseguinte, na estratégia de internacionalização. Outro aspecto importante a ser ressaltado é que os sistemas de apoio, como ensino do idioma, treinamento 
sobre a cultura do país do destino, entre outros, oferecido ao expatriado e familiares pelas empresas, antes ou depois da expatriação reduz o risco de repatriação.

Os estudos realizados até o momento mostram também que, longe de ser um processo simples e de fácil administração, o ajustamento dos indivíduos à nova situação passa por fases, e que a fase mais crítica do processo é aquela denominada de choque cultural. É nesse momento que os aspectos ligados à estrutura familiar, idioma e relacionamentos da família com a sociedade têm maior impacto na adaptação em outra cultura. Do ponto de vista prático, o presente artigo busca contribuir com o processo de expatriação, realizado pelas empresas que se internacionalizam, ao sugerir um programa de pré-expatriação que supere o mero aprendizado da língua e possibilite vivência prévia com indivíduos da nova cultura, com vistas a minimizar os efeitos do choque cultural.

Com a globalização, muitas empresas brasileiras têm mostrado interesse em instalar subsidiárias no exterior. Neste movimento, os executivos expatriados podem ter um desempenho melhor, caso suas famílias tenham bom ajustamento cultural na sociedade do país hospedeiro. Este estudo procura destacar a tendência da internacionalização das empresas brasileiras e o papel que o ajustamento cultural do executivo expatriado e de sua família pode ter para o sucesso neste processo.

Vale ressaltar também que, embora o Brasil já figure entre os três principais destinos de expatriados, que várias empresas brasileiras possuam um contingente de pessoas trabalhando fora do país, e que um número expressivo de outras empresas demonstrem interesse em fazê-lo, a literatura existente com abordagem em aspectos culturais brasileiros versus estrangeiros é escassa. Pela relevância e riqueza da teoria ora revisada, e pela importância do tema para as empresas brasileiras que têm filiais ou unidades de negócio no exterior, para aquelas corporações que pretendem fazê-lo, ou ainda para corporações estrangeiras que enviam executivos para o Brasil, sugere-se o desenvolvimento de um estudo empírico, envolvendo os diversos aspectos abordados neste artigo.

Sugerem-se adicionalmente pesquisas que possam verificar em que grau a similaridade entre culturas torna mais fácil a adaptação do expatriado e familiares à vida no novo país, bem como a influência de programas organizacionais que visem contribuir para a adaptação, facilitando a redução dos custos de repatriação de executivos e familiares e o desgaste das pessoas envolvidas no processo de expatriação. Sugerem-se alguns problemas e hipóteses preliminares que podem servir de norte para as pesquisas sugeridas, destacando-se: (1) a existência, por parte da empresa, de um perfil ideal do expatriado e de sua família, e a avaliação desse perfil no processo de seleção, se isto influencia positivamente na escolha 
de expatriados com maior chance de obter resultados satisfatórios no processo de ajustamento; (2) verificar a influência de alguns aspectos específicos da cultura brasileira, dentre eles a miscigenação étnica e cultural, no processo de ajustamento de estrangeiros no Brasil, e principalmente, de expatriados brasileiros no exterior; (3) verificar a influência que o estágio do ciclo de vida do expatriado tem no processo de ajustamento.

\section{Artigo recebido em 01.12.2003. Aprovado em 27.10.2004.}

\section{Notas}

${ }^{1}$ Conforme dados do The World Competitiveness Report (apud FUNDAÇÃO DOM CABRAL, 2002), entre 49 países pesquisados o Brasil ocupa a $47^{\circ}$ posição em relação a volume de comércio internacional. O índice de exposição (obtido por meio da soma do total de exportações com o total de importações, divididos pelo dobro do PIB) do Brasil é de 11,62, enquanto o de Singapura é 172,88, o da República Tcheca 73,18 e do Chile 31,47, o que demonstra que a inserção brasileira no comércio internacional é tímida.

${ }^{2}$ Considerada a década 1993/2002, o volume das exportações brasileiras cresceu 56,5\% - de U\$ 38,6 bilhões para U\$ 60,4 bilhões - (BRASIL, 2003), chegando a 13\% do PIB. Porém a média dos principais países com atuação no comércio internacional é de $40 \%$ do PIB, e apesar do crescimento das exportações, o índice de participação do Brasil no comércio mundial mantém-se desde 1990 na faixa de $1 \%$.

${ }^{3}$ Em recente trabalho, desenvolvido pela Revista Expressão e Fundação Getúlio Vargas - Anuário das Maiores e Melhores Empresas do Sul (2003, ano 13, vol.127), são apresentados dados da última década sobre a região Sul do Brasil que apontam um crescimento de $54,6 \%$ no volume total de exportações da região, bem como o aumento de 01 para 27 empresas com faturamento anual superior a R\$ 1 bilhão. Das 300 maiores empresas do sul do Brasil, em 2002, 186 exportaram representando $20 \%$ do faturamento total do grupo, ou 6,3 bilhões de dólares. As exportações dessas 186 empresas representam em média 31\% de suas receitas líquidas. Juntas, as 20 melhores empresas da região Sul do Brasil da década 1993/2002 venderam R \$ 151,62 bilhões, tiveram uma rentabilidade média de 14,5\% sobre o Patrimônio Líquido e o lucro foi de R\$ 16,6 bilhões. Das 20 empresas eleitas, 17 exportavam, sendo que destas 12 contam com unidades no exterior.

${ }^{4}$ Em estudo realizado com expatriados brasileiros e estrangeiros, Machado e Hernandes (2003) indicam que, a fase inicial do processo de expatriação é influenciada pela existência de uma experiência anterior fora do país. O estudo desenvolvido pelos autores, aponta que tanto para brasileiros como para estrangeiros, o impacto inicial era menor, quando os indivíduos já tinham passado por uma experiência de expatriação, mesmo que não por motivos profissionais.

${ }^{5}$ Em estudo recente com 22 mulheres, esposas de expatriados brasileiros, designados para trabalhar numa indústria química em Midland, Estados Unidos da América, com tempo de expatriação variando de menos de três a mais de dez anos, Santos (2003) identificou os estágios lua de mel, choque cultural, ajustamento e entusiasmo. Os resultados confirmam as características apontadas pelos estudos realizados anteriormente. 


\section{ReferênCIAs Bibliográficas}

\section{ALI, A. J.}

\section{Intercultural Adaptation Among} Expatriates Spouses and Children. 2003. 255 f. Tese (Phd) - Human Resource Management and International Business - University of Groningen/Groningen-Holanda. Disponível em: <http//www.ub.rug.nl/ eldoc/disc/managment/a $>$. Acesso em: 04 Aug. 2003.

\section{BAKER, J.;}

\section{IVANCEVICH, J.}

The assignment of American executives' abroad: Systematic, haphazard or chaotic? California Management Review. Berkeley, v. 13, n. 3, p. 39-44. spring 1971.

\section{BARTLETT, C. A.;}

GHOSHAL, S.

What is a global manager? Harvard Business Review. Boston-EUA, v. 70, n. 5, p. 124-32, Sept./Oct. 1992.

\section{BERRY, J.W.;}

KALIN, R.

Multicultural and ethnic attitudes in Canada: an overview of the 1991 National Survey. Canadian Journal of Behavioral Sciences. OntárioCanada, v. 27, n. 3, p. 301-320, July 1995.

\section{BLACK, J. S.}

The relationship of personal characteristics with the adjustment of Japanese expatriate managers. Management International Review. Wiesbaden-Alemanha, v. 30, n. 2, p. 119-134, 2. trim. 1990.
BLACK, J. S.;

GREGERSEN,H.B.

The Right Way to Manage Expats.

Harvard Business Review. BostonEUA, v. 77, n. 2, p. 52-62, Mar./Apr. 1999.

\section{BLACK, J. S.;}

GREGERSEN, H. B.;

MENDENHALL, $M$.

Toward a theoretical framework of repatriation adjustment, Journal of International Business Studies. Washington-EUA, v. 23, n. 4, p. 373760 4. trim. 1992.

\section{BLACK, J. S.;}

MENDENHALL, M.;

ODDOU, G.

Toward a comprehensive model of international adjustment: and integration of multiple theoretical perspectives. Academy of Management Review. New York-EUA, v. 16, n. 2, p. 292-310, Apr. 1991.

BLACK, J. S.;

STEPHENS, G. K.

The influence of the spouses on american expatriate adjustment and intent to stay in Pacific Rim overseas assigments. Journal of Management. Bloomington-EUA, v. 15-4, n. 4, p. 529-44, Dec. 1989.

BRASIL.

Ministério do Desenvolvimento. Indústria e Comércio Exterior. Siscomex e Secex. Disponível em: $<$ http://www.fininger.com.br/ imprensa/imp_dados_brasil.htm>. Acesso em: 21 set. 2003. 
CAETANO, J. R.

O Brasil é o limite? Exame, ed. 798, agos. 2003. Disponível em: <http:// www.portalexame.abril.com.br/ e di c o e s / 798 / e m p res a s / conteudo_18640.shtml.>.Acesso em: 22 set. 2004.

\section{CALIGIURI, P.}

The big five personality characteristics as predictors of expatriate's desire to terminate the assignment and supervisor-rated performance. Personnel Psychology. Durham-EUA, v. 53, n. 1, p. 67-88, spring 2000.

\section{CERTO, S.}

Administração Moderna. 3. ed. São Paulo: Makron Books, 1997, p. 469.

COPELAND, A. P.;

NORELL, S.

Spousal adjustment on international assignments: the role of social support. International Journal of Intercultural Relations. Hilo-EUA, v. 26, n. 3, p. 255-271, May 2002.

DE CIERI, H.;

DOWLING, P. J.;

TAYLOR, K. F.

The psychological impact of expatriate relocation on partners. The International Journal of Human Resource Management. Aldrshot Dartmouth Publisher, v. 2, p. 357-394, Dec. 1991.

FERREIRA, A. B. H.

Novo Dicionário da Língua Portuguesa. 2.ed. Rio de Janeiro: Editora Nova Fronteira. 1986.
FUNDAÇÃO DOM CABRAL.

Pesquisa sobre a internacionalização da empresa brasileira. Belo Horizonte, 2002. Disponível em: <http:// www.fdc.org.br>. Acesso em: 10 set. 2003.

\section{GLOBAL RELOCATION SERVICES -} GMAC

Global Relocation Trends - 2001

Survey Report, New Jersey, 2002, p. 8.

\section{HALCROW, A.}

Expats: the squandered resource. Workforce. Detroit-EUA, v. 78, n. 4, p. 42-48, Apr. 1999.

\section{HARVEY,M.G.}

The executive family: an overlooked variable in international assignments, Columbia Journal of World Business. New York-EUA, v. 20, n. 1, p. 84-92, spring 1985.

\section{HOFSTEDE, G.}

Motivation, leadership and organization: do American theories apply abroad. Organizational Dynamics. New York-EUA, v. 9, n. 1, p. 42-63, summer 1980.

HORNBY,A.S.

English-Reader's Dictionary. 2. ed. Oxford: Oxford University Press, 1979.

MACHADO, H. V.; HERNANDES, C.

AAlteridade, Expatriação e trabalho: implicações para a gestão internacional. In: ENCONTRO ANUAL DA ANPAD, 27., 2003, Atibaia. Anais... Atibaia: ANPAD, 2003. 1 CD-ROM. 
MENDENHALL, M.E.;

ODDOU, G.

The Dimensions of Expatriate Acculturation: a Review. Academy of Management Review. New York-EUA, v. 10, n. 1-10, p. 39-47, Jan. 1985.

MENDENHALL, M. E.;

DUNBAR, E.;

ODDOU, G.

Expatriate selection, training and career-pathing. A Review and a critique. Human Resource Management. New York-EUA, v. 26, n. 3, p. 331-345, fall 1987.

MILLER, E.

Regional Location and International Work Experience as Correlates of the Job Satisfaction of Expatriate Managers, Journal of Economics and Business. New York, v. 28, n. 2, p. 121-127, winter 1973.

MISA, K. F.;

FABRICATORE, J. M.

Return on investment of overseas personnel. Financial Executive. Morristown-EUA, v. 47, p. 42-46, Apr. 1979.

\section{NAUMANN, E.}

A conceptual model of expatriate turnover. Journal of International Business Studies. Washington-EUA, v. 23, n. 3, p. 499-531, third quarter 1992.

\section{NICHOLSON, N.}

A theory of work role transitions. Administrative Science Quarterly. Ithaca-EUA, v. 29, n. 2, p. 172-191, June 1984.
OBERG, K.

Culture shock: Adjustment to new cultural environment. Practical Anthropology. Alabama, EUA, v. 7, n. 4, p. 177-182, 1960.

REVISTAEXPRESSÃO e FUNDAÇÃO GETÚLIOVARGAS.

Anuário das Maiores e Melhores Empresas do Sul. Florianópolis: Editora Expressão, v. 127, ano 13, 2003.

SANTOS, C. M. B. N.

Expatriados Brasileiros nos Estados Unidos - Desafios e Conquistas. In: ENCONTRO ANUAL DA ANPAD, 27., 2003, Atibaia. Anais... Atibaia: ANPAD, 2003. 1 CD-ROM.

SCHNEIDER, S. C.;

ASAKAWA, K.

American and Japanese Expatriate Adjustment - A Psychoanalytic Perspective. Human Relations. New York-EUA, v. 48, n. 10, p. 1109-1128, Oct. 1995.

SHAFFER, M.A.;

HARRISON, D. A.

Forgotten partners of international assignments: development and test of a model of spouse adjustment, Journal of Applied Psychology. Washington-EUA, v. 86, n. 2, p. 238254, Apr. 2001.

\section{SHEPHARD, P.}

Working with Malaysians expatriates and Malaysians Perspectives. In: ABDULLAH, A. (Ed.) Understanding the Malaysian Workforce - Guidelines for Managers. 1. ed. Kuala Lumpur: Malaysian Institute of Management, 1996, p. 144-155. 
SILVEIRA, $M$. A dura vida de expatriado. VOCÊ S. A. São Paulo, Edição 47, maio 2002. Disponível em: <http:// vocesa.abril.com.br/edi 47 / 853_1.shl.>.Acesso em: 22 set. 2004.

STENING, B. W.;

HAMMER, M. H.

Cultural Baggage and Adaptation of Expatriate Americans and Japanese Managers, Management International Review. WiesbadenAlemanha, v. 32, n.1, p. 77- 8, Jan. 1992.

SULL, D. N.;

ESCOBARI, $M$.

Agora sim: prepare sua empresa para a concorrência global. Harvard Business Review. Santiago-Chile, v. 82, n. 9, Edição Brasil, p. 29-37, Set. 2004.

TUNG, R. L.

Career Issues in International Assignments. Academy of Management Executive. Briarcliff Manor-EUA, v. 2, n. 3, p. 241-244, Aug. 1988.

Selecting and Training Procedures of U.S., European, and Japanese
Multinational Corporations. California Management Review. Berkeley-EUA, v. 25, n. 1, p. 57-71, fall 1982.

Expatriates Assignments: enhancing success and minimizing failure. The Academy of Management Executive. Briarcliff Manor-EUA, v. 1, n. 2, p. 117-126, May 1987.

American Expatriates Abroad: from Neophytes to Cosmopolitans, Journal of World Business. Greenwhich-EUA, v. 33, n. 2, p. 125144, summer 1998.

ZEIRA, Y.;

BANAI, $M$.

Selection of expatriate managers in MNCs: the host-environment point of view, International Studies of Management \& Organisation. White Plains-EUA, v. 15, n. 1, p. 33-51, spring 1985.

WINDHAM INTERNATIONAL AND NATIONAL FOREIGN TRADE COUNCIL

Global Relocation Trends, Survey Reports. New York - New York Windham International, p. 77, 1996. 